\title{
An analysis of economic incentives to encourage organ donation: evidence from Chile
}

\author{
Marcela Parada-Contzen ${ }^{1 *}$ (i) and Felipe Vásquez-Lavín ${ }^{2}$
}

*Correspondence:
mparadacontzen@gmail.com
${ }^{1}$ Departamento de
Ingeniería Industrial, Facultad
de Ingeniería, Universidad
de Concepción, Edmundo
Larenas 219, Concepción,
Chile
Full list of author information
is available at the end of the
article

*Correspondence: mparadacontzen@gmail.com de Ingeniería, Universidad de Concepción, Edmundo Larenas 219, Concepción, article

\begin{abstract}
We perform a cost-benefit analysis on the introduction of monetary incentives for living kidney donations by estimating the compensation that would make an individual indifferent between donating and not donating a kidney while alive using Chilean data. We find that monetary incentives of US\$12,000 save US\$38,000 to health care system per donor and up to US\$169,871 when we consider the gains in quality of life of receiving an organ. As one allows the incentives to vary depending on the individual position on the wage distribution, the compensation ranges from US\$4214 to US\$83,953. Importantly, introducing payments to living donors payable by a third party helps patients who currently may not have access to necessary medical treatment. Therefore, exclusions in access for organs due to the monetary constraints can be prevented.
\end{abstract}

JEL Classification: 118, K32, D61

Keywords: Organ donation, Compensations to living donors, Cost-benefit analysis

\section{Introduction}

Advances in medical technology have made organ transplants one of the best health treatment alternatives for several diseases, generating a significant increase in organ demand. However, the supply of organs, both from living or postmortem donors, has not increased at the same rate (Howard 2007). Policy makers have suggested different strategies for increasing organ donation, including the introduction of financial and monetary incentives (Stoler et al. 2017).

The scarcity of organs for transplantation is a worldwide problem. In the United States, 10,000 people die every year while waiting for an organ, and the median waiting time goes from 2 to 6 years (Beard et al. 2013; Roth et al. 2005). In Western Europe, approximately 40,000 patients are waiting for an organ (Mossialos et al. 2008). Developed countries tend to have higher cadaveric donation rates than developing countries, while, the reverse is true for living donation (International Registry in Organ Donation and Transplantation 2017).

Based on the discussion on incentivizing organ donation using financial mechanisms, this paper performs a cost-benefit analysis on the introduction of monetary incentives for living kidney donations in a developing country. We consider the case for Chile, 
where, according to the National Transplant Corporation, 2000 patients are enrolled on a waiting list, while the average number of donors per year is 125 . As data for non-market economic valuation tend to be scarce in Latin America, our results provide information for policymakers about the economic benefits of implementing compensation for kidney donations in developing countries. ${ }^{1}$

For the U.S., there is mixed evidence concerning the effect that the introduction of monetary incentives would have on organ donation rates (Bilgel and Gelle 2015; Venkataramani et al. 2012; Wellington and Sayre 2011; Schnier et al. 2018). Outside the U.S., some countries have implemented policies in this regard. For instance, Israel implemented a reform in 2012 that allows compensation to living donors (Lavee et al. 2013).

Preliminary policy evaluations for the Israeli case indicate that there was a positive response in donation rates (Lavee et al. 2013). This policy includes the following: earning loss reimbursement before the donation and during recovery; transportation refund for the donor and relatives during and after the donation; and a 5-year reimbursement of medical expenses, work capability loss, life insurance, and psychological consultation and treatment. Together with that policy, Israel implemented a priority condition in organ donor waiting lists to individuals who are registered as donors, a law that has also been implemented in Singapore, China, and Chile (Stoler et al. 2017). Among developing countries with high donation rates, Iran is also an interesting case since it is the only country where open payments to livings donors are allowed (Bilgel 2013).

This paper considers the model developed by Becker and Elias (2007), where the donor's compensation includes reimbursement for the donation procedure as well as compensation for loss of earnings and increased risks of death and injury. Based on this, we estimate the compensation that would make an individual indifferent between donating and not donating a kidney while alive, relying on estimates of the value of statistical life (VSL) and injury (VSI) found in the literature. We use estimates provided by the literature from both revealed preferences (RP, hedonic wage method) and stated preference approaches (SP, choice experiments). We then compare this amount with the benefits that an additional donor provides to the health system through costs avoided. We also evaluate whether or not the estimated compensation based on Becker's analysis is sufficient to induce donation.

The contributions of this paper are the following. First, we extend the policy evaluation of introducing compensation to living donors using a cost-benefit analysis rather than a cost-effectiveness analysis. Although this has been recently done for the U.S., evidence for other countries is very rare. Second, we evaluate the compensation across the wage distribution and, therefore, consider the possibility that participation outcomes could be unequal, as payments would induce poor people to participate while the wealthiest segments would exclude themselves. Third, we evaluate whether the payments (based on Becker's analysis) are sufficient to induce donations. This problem is an important issue that has not been empirically studied in detail.

The estimated compensations range between US $\$ 4214$ and US $\$ 83,953$. The results indicate that a compensation computed at the 95th percentile of the distribution would

${ }^{1}$ Chile is classified as a developing country by the International Monetary Fund and as a high-income OCDE country by the World Bank. 
still generate savings to the health system, even when using conservative values for the cost-benefit analysis. The efficiency gain allows for the introduction of participation premiums to the poor segments to avoid unequal payments. This last result is relevant as it might help to alleviate ethical concerns on participation outcomes.

This paper also estimates the value of a kidney for a donor using the prevalence of chronic kidney disease in the Chilean population and provides evidence that individuals' expected costs, in terms of lifespan and quality of life, of having a kidney disease range between US\$1085 and US\$110,875. Consequently, we consider these values to represent the lower bound of individuals willing to pay for a healthy organ so that they can avoid having a kidney disease in the future. The compensation to donors should at least be commensurate with their own willingness to pay for an organ. The estimated kidney values are higher than the estimated compensation but still affordable given the savings that an additional donor provides to the health system. We propose a premium that is payable over the 90th percentile of the wage distribution.

\subsection{Background}

Since kidney donation can come from a living donor and it is the most frequently transplanted organ coming from living donation. Consequently, there is great controversy regarding the best mechanism, if any, to encourage donations from living people. Answering this question inevitably invokes ethical and philosophical issues involved in organ donations. Economists have analyzed the problem from a "market perspective" in which the scarcity of the good is modeled as a market failure (Beard et al. 2013). Researchers have evaluated the impact that economic instruments could have on supply and have proposed economic incentives to encourage donation (Becker and Elias 2007).

Diesel (2010) shows that out of 72 economists who have studied organ donations, $68 \%$ are in favor of the "liberalization of the market," that is, the introduction of economic incentives to increase organ supply. Nevertheless, the specific policy design of this incentive varies among researchers. Some propose cash transfers to donors or beneficiaries, while others propose non-monetary benefits, such as memorial services or access to medical treatments (Gaston et al. 2006; Howard 2007; Diesel 2010). Supporters of market mechanisms argue that the relevant issue is that incentives could reduce the gap between supply and demand and prevent a significant number of avoidable deaths (Beard et al. 2013). However, more importantly, there is a consensus among researchers that instead of a simple "market for organs", the health system should introduce a regulated compensation system to living donors, in which a third party defines the amount of compensation (Barnett et al. 2001; Matas 2004; Becker and Elias 2007). Of course, there is also controversy surrounding this argument; Brooks (2003) claims that a government payment for an organ may be highly inefficient. Regardless, there is evidence that this compensation would be worth the investment given the savings that it could generate (Barnett et al. 1999).

It may be seen as unethical to commoditize organs because it could generate perverse incentives, inequalities, and reductions of altruistic donations (Liverman and Childress 2006; Beard et al. 2013). Furthermore, the examination of this problem exclusively from an economics perspective might not be advisable for making decisions in any modern society (Abadie and Gay 2006). Nevertheless, we think it is important to contribute to 
the debate from all possible angles to provide information for policymakers; if a compensation policy passes the cost-benefit analysis, then the final design should require a combination of economic incentives along with regulations and mechanisms that assure that policies are in harmony with society's moral views.

Some authors claim that it is impossible to estimate the real impact of such a policy until payments are allowed (Barnett et al. 2001; Becker and Elias 2007). Since payments have not been incorporated, most of the attempts to measure the efficiency of this policy have used a cost-effectiveness analysis. Evans and Kitzmann (1998) compared dialysis to a kidney transplant and concluded that the kidney transplant is the best alternative in terms of quality of life and long-term costs. Matas and Schnitzler (2004) claim that because the government of the United States or private agencies already pay for the long-term treatment of dialysis, it is feasible to pay a kidney donor and, therefore, save the cost of dialysis, an amount estimated between US\$90,000 and US\$270,000. Becker and Elias (2007) propose a compensation method and provide estimates in the range of US\$7600 to US $\$ 27,700$ for a kidney per living donor in the United States, which represents a significant efficiency gain [US\$122,700 per donor based on Held and Port (2003)]. For developing countries, Harrison et al. (2010) estimate savings in the range of US\$50,616 to US\$182,218 for the Chilean health system per additional donor.

\section{Materials and methods}

\subsection{The value of statistical life and safety}

We rely on estimates of the value of a statistical life (VSL) and the value of a statistical injury (VSI) to perform the cost-benefit analysis. The VSL is defined as the willingness to pay to reduce fatal risk, while the VSI is the willingness to pay to reduce a non-fatal risk (or injury risk). In this setting, the hedonic wages method (HWM) is the most common approach used to estimate the VSL and VSI (Viscusi 1993; Viscusi and Aldy 2003). It recovers the VSL and VSI after estimating the wage-risk trade-off, relying on the idea that wage differences for diverse jobs reflect differences in the level of risk of death and injury faced by workers (Viscusi and Aldy 2003).

Estimates for Chile are in the range of US\$5 to US\$13.7 million for the VSL and approximately 33,000 dollars for the VSI (Parada-Contzen et al. 2013). These are the only VSL and VSI estimates using revealed preferences for Chile. To estimate the VSL and VSI, they use a cross-section of the National Socio-Economic Survey and statistics from the Chilean Safety Association for the year 2006. They estimate a hedonic log-wage equation while considering correction for selection into the labor market and endogeneity bias arising due to simultaneous determination of observed wages and risks. While they reduce potential sources of estimation bias, it is important to note that the results are only representative of Chilean workers as they rely on labor market data. In the estimation, they incorporate both fatal and non-fatal risk as control variables in the wage equation, together with other individual and job characteristics. ${ }^{2}$ Final estimates are obtained after implementing a Heckman correction for labor market selection and an

\footnotetext{
${ }^{2}$ In particular, they incorporate individual characteristics such as schooling, work experience, its squared, gender, and the Mills ratio for selection into the labor market. Into training and job information variables, they incorporate tenure, daily hours worked, work contract status, specific job training status, firm size, and geographical location using the Chilean administrative division for territorial organization.
} 
instrumental variable approach that accounts for endogeneity between risks and wages. While they suggest that future work should consider further disaggregation of the risk data, there is no new data available for Chile for addressing this limitation. Recent studies, provide estimates between 0.61 and 8.68 million dollars for the VSL but do not consider VSI estimations (Parada-Contzen 2019).

Due to the scarce availability of estimates for the VSL in several developing countries, some researchers extrapolate the VSL estimates using North American, European, and Asian VSL estimates, adjusting by per capita GDP. In the case of Chile, indirect estimates are approximately US $\$ 0.64$ to US\$0.96 million (Miller 2000; Bowland and Beghin 2001; De Blaeij et al. 2003; Bellavance et al. 2009; Hammitt and Robinson 2011).

Another approach that has been broadly used to estimate the VSL is the stated preference (SP) method (Ortuzar and Cifuentes 2000; Rizzi 2003; Iraguen and Ortuzar 2004; Hojman et al. 2005). Here, respondents face hypothetical scenarios in which they can express their preferences for different states of nature which differ in their implicit risk of death. The VSL can be obtained using optimal design approaches to select the levels of the attributes faced by respondents. Estimates for Chile using SP provide values from US\$0.28 million (Rizzi 2003) to US\$5.2 million (GreenLabUC 2014), with several values in between (Ortuzar and Cifuentes 2000; Rizzi 2003; Iraguen and Ortuzar 2004). SP reports values that came from different risk causes, such as road safety and air pollution. All estimates available using SP for Chile are lower than the values provided by ParadaContzen et al. (2013); therefore, using the latter value provides a lower bound of the net benefits associated with allowing kidney transactions.

\subsection{Becker and Elias' compensation framework}

Becker and Elias (2007)'s model for compensation for donors relies on the idea that donors should be compensated for additional costs, such as losses in income and increasing mortality and injury risks. Examples of monetary costs could be the cost of surgery and the forgone income while donors are engaged in donation procedures. A living kidney donor faces higher mortality risks during the procedure and risk of reducing his or her quality of life as a consequence of the donation. Specifically, the resulting loss in quality of life could cause challenges such as health conditions, certain types of job restrictions, or restricted recreational activities. As a result, the individual's reservation price has three components: monetary compensation for an increase in the risk of death, monetary compensation for the reduction in quality of life and monetary compensation for the time allocated to surgery and recovery.

Conceptually, the reservation price captures the minimum amount that an individual should receive to compensate for the economic costs of participating in an organ donation process. Therefore, any incentives program should at least consider this amount. Economically, the reservation price is the money amount that leaves the individual indifferent between the utility from not donating an organ and the expected utility of being a living donor, considering its mortality and injury risks. This paper relies on Becker and Elias (2007)'s model for the estimation of this amount. For these purposes, we estimate the three components they describe using data from Chile.

The first component is computed by weighting the VSL, which corresponds to the amount of money that an average person requires to accept a marginal increase in the 
probability of death. Further, Becker and Elias (2007) calculate the second component using an arbitrary value and performing a sensitivity analysis to see how the results change as different quality of life values are used. For the second component, we alternatively weight the VSI, or the amount of money that an average person requires to accept a marginal increase in the probability of injury, by the risk of a post-surgery complication. We additionally evaluate different quality of life components to see how the results change. Finally, the forgone income due to the time spent in surgery and recovery is evaluated using labor market data. We follow the same approach.

Note that we also compute the compensations across the wage distribution. For these purposes, we consider the specific VSL and VSI depending on the individual's position in the distribution. For this computation, the average wage-risk trade-offs are considered while specific wage per decile is used for obtaining the VSL and VSI, and thus, the first and second component of Becker and Elias (2007)'s model. For the third component, we use the forgone income using the percentiles wages.

In this paper, we also consider the option value of an organ. Differently to the reservation price, the option value relates to the individual's willingness to accept payments. For this calculation, we consider the expected costs of suffering kidney disease. The economic reasoning behind this concept follows the idea that if an individual can pay to avoid the loss of any good, she should be compensated for at least that willingness to pay to avoid the loss to induce her to give that good away. Empirically, the reservation price and the option value of an organ may differ. In this case, the option value would represent the required money to incentivize participation in an organ donation program.

\subsection{Data sources}

We estimate the reservation price of a kidney using the VSL and VSI estimates proposed by Parada-Contzen et al. (2013). To examine the distribution of payments, we replicate their method and sample and estimate payments across the wage distribution. In particular, we use the same cross-section (2006) of the National Socio-Economic Survey and statistics from the Chilean Safety Association. We construct the same estimation sample than the one described in Parada-Contzen et al. (2013) and reestimate the hedonic log-wage equation using the same observed characteristics. As in the benchmark paper, we correct for both selection and endogeneity bias using the methodology suggested by Parada-Contzen et al. (2013). To compute the distribution of values for the VSL and VSI, we use the estimated wage-risk trade-offs for the entire sample and the specific observed wage per decile. With this computation, we obtain an average VSL and VSI per decile of the observed wage distribution.

Data regarding the fatal risk, non-fatal risk and recovery time associated with kidney extractions were obtained from the Catalan Transplant Foundation since there are no validated data available for Chile or other Latin American countries with similar characteristics. Nevertheless, Spain has a very advanced and sophisticated donation system and, therefore, has reliable data. Based on these data, the fatal risk of an organ extraction surgery is $0.045 \%$, and the risk of complications derived from the extraction is $13 \%$. The average recovery time is 3 months.

For measuring benefits, we rely on the work of Harrison et al. (2010). They model the benefits and costs of alternative treatments for kidney diseases (i.e., dialysis and transplant) and compute the system's present value of savings associated with a transplant since 
Table 1 Components for a kidney compensation for transplantation (US\$ of 2013)

\begin{tabular}{lcccr}
\hline Item & Estimates & \multicolumn{2}{l}{ Sensitivity on VSI } & \\
\cline { 3 - 5 } & $\mathbf{( 1 )}$ & $\mathbf{( 2 )}$ & $\mathbf{( 3 )}$ & $\mathbf{( 4 )}$ \\
\hline VSI & 33,016 & 10,000 & 20,000 & 40,000 \\
Compensation for & & & & \\
Time loss & 1876 & 1876 & 1876 & 1876 \\
Death risk & 6179 & 6179 & 6179 & 6179 \\
Quality risk & 4292 & 1300 & 2600 & 5200 \\
Reservation price & 12,347 & 9355 & 10,655 & 13,255 \\
Procurement costs & 3426 & 3426 & 3426 & 3426 \\
Total cost $^{\mathrm{b}}$ & 15,773 & 12,781 & 14,081 & 16,681 \\
\hline
\end{tabular}

a Procurement costs do not enter the individual compensation as it is not part of the reservation price

b Total cost when considering that procurement costs are not covered by the health insurance. (a) Risk of Death Component $=$ Risk of Death $\times$ Value of a Statistical Life. According to data of the Catalan Transplant Foundation, the risk of death in a kidney extraction surgery is $0.045 \%$. (b) Quality of life component $=$ risk of a non-fatal complication $\times$ value of statistical injury. The risk of a non-fatal complication is $13 \%$. (c) Value of time $=$ monthly income $\times$ time of recovery. The time of recovery $=3$ months. (d) Reference value for VSL $=$ US\$13,731,842. Reference value for VSI in table

dialysis costs are avoided. These costs include items such as initial surgery, pre-transplantation, and follow-up studies, and immunological therapy. For the dialysis treatment, there are specific costs associated with blood treatments, such as hemodialysis and peritoneal dialysis. That study reports that each new donor would generate savings of US\$50,616 for the Chilean health system. Furthermore, when adding the benefits of improving the recipient's length and quality of life by weighting the time spent by the patient in different health statuses and correcting by life years, the savings per donor increases to US\$182,218. Throughout the paper, we refer to the first value as savings in costs and to the second value as savings in costs plus benefits in quality of life (QALY). The benefits in QALY computation follow the standard methodology in the literature (Harrison et al. 2010). Data on procurement costs are obtained from Dominguez et al. (2011).

Lastly, data for chronic kidney disease prevalence rates are obtained from the Chilean population. Estimates from the first wave of the Chilean National Health Survey in 2003 (in Spanish, Encuesta Nacional de Salud) report that 10-14\% of the adult population has chronic kidney disease in 1 of its 5 levels (for details, see Alvo (2009) and Flores (2010)). Specifically, $5.7 \%$ of adults are in level $3,0.2 \%$ are in level 4 , and $0.1 \%$ are in level 5 . The remaining adults with chronic kidney disease are in levels 1 and 2. Level 5 is the most severe category. Note that patients in category 5 are in dialysis treatment if no kidney is available for transplantation, while patients in level 4 are candidates for dialysis treatment or a kidney transplant.

\section{Results}

\subsection{Compensation to living donors}

The estimated compensation is presented in Table 1. Column 1 presents the results using the hedonic estimation for VSL and VSI, while columns 2, 3, and 4 evaluate different quality of life components. For the estimated VSL and VSI, the compensation to accept a higher probability of death is US\$6179 (VSL"risk of death.... the compensation for a reduction in the quality of life is US $\$ 4292$ (VSI"risk of injury $=33,016 \times 13 \%$ ), and the compensation for recovery time is US $\$ 1876$. 
To compute the total "price" or cost, we input a cost of US $\$ 3426$ for procurement costs (Dominguez et al. 2011). But, note that the procurement cost does not enter the individual reservation prices. In particular, procurement costs enter the compensation depending on the legal framework for living donations. Since the procurement costs in Chile are paid by the recipient's health insurance, which is subsidized by the government, we do not consider the extraction cost as part of the compensation to induce donation.

As a result, the reservation price for a kidney is estimated to be US\$12,347. We also adjust the payment considering variation in the VSI, with reservation prices that range between US\$9355 and US\$13,255.

To compute the efficiency of introducing payments to living donors, we consider the benefits per donor of a transplant estimated by Harrison et al. (2010). Since they present benefits to the system with and without additional benefits due to improvements in quality of life after transplantation, we are also able to consider both cases. For the computation of both efficiency measures, we just need to subtract the reservation price to the amounts estimated by Harrison et al. (2010). Thus, we have that per donor, a compensation of US $\$ 12,347$ generates savings of US $\$ 38,269$ (= US $\$ 50,616-12,347$ ). Furthermore, if we consider the benefits gains for the patient due to quality of life improvement, we have savings of US\$169,871 (= US\$182,218 - 12,347). Based on this information, introducing monetary incentives for kidney donations of US\$12,347 would confer savings to the health care system in the range of US\$38,269-169,871.

Since VSL and VSI values are wage-dependent, we now compute the reservation price for the entire wage distribution and not only at the mean. The results are shown in the top panel of Table 2. The reservation price ranges between US $\$ 788$ and US $\$ 80,528$ (Column 5) depending on the specific compensations for time loss (column 2), death risk (column 3) and quality risk (column 4) depending on the wage percentile. The reservation prices are computed by adding these three compensations per decile.

Savings to the health system are presented in the bottom panel of Table 2. Since the compensations vary according to the individual's position in the wage distribution, savings to the system also vary depending on the specific compensation. For computing the savings to the system, we subtract the reservation price in column (5) to the amounts estimated by (Harrison et al. 2010). ${ }^{3}$ As a result, savings to the health system rangeUS $\$ 29,912$ (costs) to US $\$ 49,829$ (or between US $\$ 101,690$ and US $\$ 181,431$ when considering benefits in QUALYs). Since savings to the system reported by Harrison et al. (2010) are fixed amounts that do not depend on the wage distribution, while the reservation price does, variation in savings only come from differences in the compensations.

As a result, compensations at the 95th percentile are efficient to the health care system under a conservative measure of benefits. These computations are used to argue that introducing premiums to the first deciles of the distribution still generates savings to the health care system and may be a way to address the unequal payment issue discussed in Sect. 1.

\footnotetext{
${ }^{3}$ For example, For the percentile 10\%, savings in costs equal US\$47,465 $=50,616-3,151$ and savings in costs plus benefits in QALY equal US\$179, $067=182,218-3151$.
} 
Table 2 Estimated kidney compensation and savings for transplantation across the wage distribution (US\$ of 2013)

\begin{tabular}{|c|c|c|c|c|c|}
\hline \multirow[b]{3}{*}{ (1) } & \multicolumn{3}{|l|}{ Compensation for } & \multirow{3}{*}{$\begin{array}{l}\text { Reservation price } \\
\text { (5) }\end{array}$} & \multirow{3}{*}{$\begin{array}{l}\text { Total } \\
\text { (6) }\end{array}$} \\
\hline & Time loss & Death risk & Quality risk & & \\
\hline & (2) & (3) & (4) & & \\
\hline Mean & 1876 & 6179 & 4292 & 12,347 & 15,773 \\
\hline \multicolumn{6}{|c|}{ Percentile } \\
\hline 1 & 120 & 394 & 274 & 788 & 4214 \\
\hline 5 & 306 & 1008 & 700 & 2013 & 5439 \\
\hline 10 & 479 & 1577 & 1095 & 3151 & 6577 \\
\hline 25 & 734 & 2418 & 1680 & 4832 & 8258 \\
\hline 50 & 1101 & 3627 & 2519 & 7248 & 10,673 \\
\hline 75 & 1835 & 6045 & 4199 & 12,079 & 15,505 \\
\hline 90 & 3639 & 11,986 & 8326 & 23,951 & 27,377 \\
\hline 95 & 5984 & 19,712 & 13,692 & 39,387 & 42,813 \\
\hline \multirow[t]{4}{*}{99} & 12,235 & 40,301 & 27,993 & 80,528 & 83,954 \\
\hline & \multicolumn{5}{|c|}{ Savings to the system } \\
\hline & Savings in costs & Savings in costs & & & \\
\hline & & + Benefits in QALY & & & \\
\hline Mean & 38,269 & 169,871 & & & \\
\hline \multicolumn{6}{|c|}{ Percentile } \\
\hline 1 & 49,829 & 181,431 & & & \\
\hline 5 & 48,603 & 180,205 & & & \\
\hline 10 & 47,465 & 179,067 & & & \\
\hline 25 & 45,785 & 177,387 & & & \\
\hline 50 & 43,369 & 174,971 & & & \\
\hline 75 & 38,537 & 170,139 & & & \\
\hline 90 & 26,666 & 158,268 & & & \\
\hline 95 & 11,229 & 142,832 & & & \\
\hline 99 & $-29,912$ & 101,690 & & & \\
\hline
\end{tabular}

(a) Risk of death component $=0.00045 \times$ VSL. (b) Quality of life component $=0.13 \times$ VSI. (c) Value of time $=3 \times$ wage. Wage is percentile-specific. (d) Total cost does not consider a health care system that covers the procurement cost. We present the total compensation in case the extraction surgery is not covered by the recipient's health insurance. This amount is included in the benefits computations by Harrison et al. (2010) so it is not added in the total cost for the analysis. (e) Savings in costs consider only savings to the health system $(U S \$ 50,616)$ minus the compensation payment. Benefits in QALY add gains of improving the quality of life of patients after receiving an organ (additional benefits of US\$131,602 over the savings in costs to the health system). Savings in costs plus benefits in QALY report benefits of US\$182, 218 minus the compensation payment

\subsection{Value of a kidney for a donor}

As a proxy for the lowest bound of the willingness to accept payments, we compute the option value of a kidney for a donor by estimating the expected cost of suffering kidney disease. For this calculation, we consider both quality of life effects (weighting the VSI for these purposes) and risks of suffering malfunctioning kidney conditions (weighting the VSL for these purposes). The reasoning behind these computations follows the same argument than Becker and Elias (2007).

If individuals can avoid the expected cost of suffering a kidney disease by paying for an organ for transplantation (e.g., they will replace their malfunctioning kidney), then a donor's value of a kidney is equivalent to her willingness to pay for avoiding the expected cost of having a chronic kidney disease. If individuals are at least compensated for these 
expected costs, then they will be willing to participate in the organ donation mechanism. The reasoning behind this idea is equivalent to any standard economic decision: if an individual can pay to avoid the loss of any good, she should be compensated for at least that willingness to pay to avoid the loss to induce her to give that good away. ${ }^{4}$

We propose that the compensation to living donors should be at least the individual's expected cost of having a chronic kidney disease. To begin with the analysis, we consider two pessimistic scenarios: case (i) the highest estimated prevalence rate is considered (i.e., 14\%) and case (ii) all individuals in the fourth and fifth category have a non-functioning kidney. For case (i), the option value is computed per percentile weighting the VSI by 0.14 and the VSL by 0.001 . For case (ii), the option value is computed per percentile weighting the VSI by 0.10 and the VSL by 0.003 . The risks data enter according to the Chilean National Health Survey (2003). Results for both cases, including option values and participation premiums, are presented in Table 3.

For case (i), we find donor's valuation at the mean is US\$18,321, while that for case (ii) the donor's valuation at the mean is US $\$ 44,398$. The difference between the values under both scenarios is solely given by the different assumptions on prevalence rates versus the risk of having a malfunctioning kidney.

Conditional on the scenario, we consider this computation to be a lower bound of an individual's valuation (i.e., for each scenario, some characteristics are not entering into the calculations). Specifically, some individual unobservable variables are not being considered. For example, individuals may value other variables such as the importance of not participating in optional surgeries or keeping both of her kidneys in case a relative needs one. An important implication for policy design is that this value is higher than the reservation price computed using Becker and Elias (2007) compensation method, so the compensation computed in the previous section should not be enough to induce donation.

However, since there are savings of a transplantation procedure versus other alternatives in both cases, it is possible to pay higher compensations. From the previous section, we have that savings at the mean are at least US $\$ 38,269$ and up to US $\$ 169,871$ when considering benefits in QALY. Therefore, parts of these savings can be used to induce donation by compensating individuals the amounts that correspond to their individual valuation. In this setting, increased compensations would take the form of a participation premium.

Participation premiums needed to induce donation are also presented in Table 3 (column 3). This premium is computed subtracting the reservation price in Table 2 calculated using Becker and Elias (2007)'s model to the Option Value (column 2). Important is to note that participation premiums are required at any point of the wage distribution, meaning that Becker and Elias (2007)'s amounts are not enough to induce participation at any point of the distribution. As we move along the distribution, this premium increases.

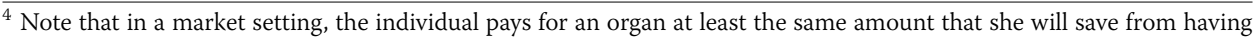
the disease. While we are not suggesting that such a market should exist, we are using economic reasoning to calculate how much an individual will save if she has such a disease.
} 
Table 3 Option value and participation premiums to induce donation (US\$ of 2013)

\begin{tabular}{|c|c|c|c|c|c|}
\hline & \multirow{3}{*}{$\begin{array}{l}\text { Wage } \\
\text { (1) }\end{array}$} & \multirow{3}{*}{$\begin{array}{l}\text { Option } \\
\text { Value } \\
\text { (2) }\end{array}$} & \multirow{3}{*}{$\begin{array}{l}\text { Participation } \\
\text { Premium } \\
\text { (3) }\end{array}$} & \multicolumn{2}{|l|}{ Savings } \\
\hline & & & & Costs & Costs + QALY \\
\hline & & & & (4) & (5) \\
\hline \multicolumn{6}{|c|}{ (i) Prevalence rate of $14 \%$ for kidney chronic disease } \\
\hline Mean & 625 & 18,321 & 5974 & 32,295 & 163,897 \\
\hline \multicolumn{6}{|c|}{ Percentiles } \\
\hline 1 & 40 & 1169 & 381 & 49,447 & 181,049 \\
\hline 5 & 102 & 2987 & 974 & 47,629 & 179,231 \\
\hline 10 & 160 & 4675 & 1524 & 45,941 & 177,543 \\
\hline 25 & 245 & 7169 & 2338 & 43,447 & 175,049 \\
\hline 50 & 367 & 10,754 & 3506 & 39,862 & 171,464 \\
\hline 75 & 612 & 17,923 & 5844 & 32,693 & 164,295 \\
\hline 90 & 1213 & 35,538 & 11,587 & 15,078 & 146,680 \\
\hline 95 & 1995 & 58,443 & 19,056 & $(7827)$ & 123,775 \\
\hline 99 & 4078 & 119,488 & 38,960 & $(68,872)$ & 62,730 \\
\hline \multicolumn{6}{|c|}{ (ii) Individuals in fourth and fifth category have a non-functioning kidney } \\
\hline Mean & 625 & 44,398 & 32,051 & 6218 & 137,820 \\
\hline \multicolumn{6}{|c|}{ Percentiles } \\
\hline 1 & 40 & 2833 & 2045 & 47,783 & 179,385 \\
\hline 5 & 102 & 7239 & 5226 & 43,377 & 174,979 \\
\hline 10 & 160 & 11,330 & 8179 & 39,286 & 170,888 \\
\hline 25 & 245 & 17,374 & 12,542 & 33,242 & 164,844 \\
\hline 50 & 367 & 26,060 & 18,813 & 24,556 & 156,158 \\
\hline 75 & 612 & 43,434 & 31,355 & 7182 & 138,784 \\
\hline 90 & 1213 & 86,121 & 62,170 & $(35,505)$ & 96,097 \\
\hline 95 & 1995 & 141,626 & 102,239 & $(91,010)$ & 40,592 \\
\hline 99 & 4078 & 289,560 & 209,031 & $(238,944)$ & $(107,342)$ \\
\hline
\end{tabular}

(a) In panel (i), the option value is computed per percentile weighting the VSI by 0.14 and the VSL by 0.001 . In panel (ii), the option value is computed per percentile weighting the VSI by 0.10 and the VSL by 0.003 . (b) Negative values (costs) in parentheses. (c) Participation premiums are computed subtracting the reservation price in Table 2 to the option value. (d) Savings in costs consider only savings to the health system. Benefits in QALY consider gains of improving the quality of life of patients after receiving an organ (see Harrison et al. (2010) and references therein)

Let us take the following examples. For case (i), at the mean, since the donor's valuation is US\$18,321 and the proposed compensation is US\$12,347, then a participation premium of US\$5974 ( $=U S \$ 18,321-12,347$ ) should be offered. Across the wage distribution, the premium goes from US $\$ 381(=$ US $\$ 1,169-788)$ to US $\$ 38,960$ $(=U S \$ 119,488-80,528)$. As a result, increasing the payment is possible up to the 90th percentile of the wage distribution when considering the values of conservative costs and is possible up to the 99th percentile when considering the benefits of improving the patient's quality of life (see details in Table 3).

For case (ii), at the mean, the proposed participation premium corresponds to US\$32,051 (=US\$44,398 - 12,347). Depending on the individual's position in the wage distribution, the premium ranges between US\$2045 (=US\$2, $833-788)$ and US $\$ 209,031$ (=US $\$ 289,560-80,528$ ). In this scenario, because participation premiums are higher relative to case (i), increased participation premiums are efficient up to the 75th percentile of the wage distribution for conservative costs savings and up to the 95\% of the distribution when adding QALY benefits. 
Despite the different specific values of participation premiums and savings amounts computed under case (i) and case (ii), the general result is prevalent and robust: participation premiums are efficient up to the 75th percentile even under the pessimistic scenario considering all individuals in the fourth and fifth category have a non-functioning kidney.

Once again, because there might be ethical tensions concerning payments, one could argue that all participation premiums can be computed at the 75th percent of the distribution and distributed to individuals no mattering their relative position in the distribution. ${ }^{5}$ In this setting, the relevant policy instrument from this analysis is that a participation premium of US $\$ 31,355$ is efficient to the system considering conservative estimates and would incentivize individuals from the 75th percentile and below to join in the mechanism. When considering all benefits, even participation premiums to induce the richest segment of the population to participate at the 95th percentile (e.g., US\$102,239), would generate benefits to the health care system while relieving ethical strains.

Note that this calculation assumes that an individual has two kidneys, and, therefore, she can actually donate one. While the risks of suffering kidney disease with one kidney are not different than when the individual has two kidneys, the individual might value the good differently. In that case, the option value of the individual should be higher, and therefore, risk premiums should be higher than the ones presented here. It is important to note that the difference in valuations does not come from differences in risks but due to individual appreciations of the relative scarcity of the good interacted with other characteristics such as risk aversion. Still, in that case, organ donation is to plausible, while eventually the option values could be computed.

To conclude this section, we also perform a sensitivity analysis considering a less pessimistic scenario where the lowest prevalence rate (i.e., 10\% rather than 14\%) and lowest non-functioning risks (i.e., only individuals in the fifth category have a non-functioning kidney) are considered.

The general pattern of results holds. The savings to the system increased as participation premiums in this last scenario are smaller. With respect to case (i), option values and participation premiums decreased but not substantially. It is efficient to compensate individuals by their option value up to the 90th percent of the distribution when only considering savings in costs, and efficient for the entire distribution when adding benefits due to improvements in individuals' life quality. With respect to case (ii), the differences in option values and participation premiums are even bigger. All details are available in Table 4 and are presented for the reader's analysis.

\subsection{Evaluation using stated preference estimates}

We now compare the results presented above with the estimates obtained using stated preference estimates for Chile. As the estimates for the VSL are lower for stated preference estimates than for the hedonic estimation, the estimated reservation price is lower, increasing the efficiency of introducing payments to living donors. The SP studies and

${ }^{5}$ This case considers the second pessimistic scenario (i.e., case ii) and the conservative costs savings computation (i.e. no QALY included). 
Table 4 Option value of a kidney and participation premiums in an optimistic scenario (US\$ of 2013)

\begin{tabular}{lccccc}
\hline & Wage & Option value & $\begin{array}{l}\text { Participation } \\
\text { premium }\end{array}$ & Costs & $\begin{array}{l}\text { Savings } \\
\text { Costs + QALY }\end{array}$ \\
& $\mathbf{( 1 )}$ & $\mathbf{( 2 )}$ & $\mathbf{( 3 )}$ & $\mathbf{( 4 )}$ & $\mathbf{( 5 )}$ \\
\hline Mean & 625 & 17,000 & 4653 & 33,616 & 165,219 \\
Percentiles & & & & & \\
1 & 40 & 1085 & 297 & 49,531 & 181,134 \\
5 & 102 & 2772 & 759 & 47,844 & 179,447 \\
10 & 160 & 4338 & 1187 & 46,278 & 177,881 \\
25 & 245 & 6653 & 1821 & 43,963 & 175,566 \\
50 & 367 & 9979 & 2731 & 40,637 & 172,240 \\
75 & 612 & 16,631 & 4552 & 33,985 & 165,588 \\
90 & 1213 & 32,977 & 9026 & 17,639 & 149,242 \\
95 & 1995 & 54,230 & 14,843 & $(3614)$ & 127,989 \\
99 & 4078 & 110,875 & 30,347 & $(60,259)$ & 71,344 \\
\hline
\end{tabular}

(a) Option value is computed per percentile weighting the percentile VSI by 0.10 and the percentile VSL by 0.001 according to the Chilean National Health Survey (2003). (b) Negative values (costs) in parentheses. (c) Participation premiums are computed subtracting the reservation price in Table 2 to the option value. (d) Savings in costs consider only savings to the health system. Benefits in QALY consider gains of improving the quality of life of patients after receiving an organ (see Harrison et al. (2010) and references therein)

Table 5 Components for a kidney compensation for transplantation using stated preferences studies (US\$ of 2013)

\begin{tabular}{|c|c|c|c|c|c|c|c|}
\hline \multirow[t]{2}{*}{ Reference VSL } & \multirow[t]{2}{*}{ VSL } & \multicolumn{2}{|c|}{ Compensation for } & \multirow{3}{*}{$\begin{array}{l}\text { Reservation } \\
\text { price } \\
\text { (5) }\end{array}$} & \multirow{3}{*}{$\begin{array}{l}\text { Total } \\
\text { (6) }\end{array}$} & \multicolumn{2}{|c|}{ Savings to the system } \\
\hline & & Death risk & Quality risk & & & In costs & In costs + QALY \\
\hline (1) & (2) & (3) & (4) & & & (7) & (8) \\
\hline $\begin{array}{l}\text { Ortuzar and Cifuentes } \\
\text { (2000) (road safety) }\end{array}$ & 0.68 & 306 & 4292 & 6474 & 9900 & 44,143 & 175,745 \\
\hline $\begin{array}{l}\text { Ortuzar and Cifuentes } \\
\text { (2000) (air pollution) }\end{array}$ & 0.41 & 185 & 4292 & 6352 & 9778 & 44,264 & 175,866 \\
\hline Rizzi (2003) & 0.28 & 126 & 4292 & 6294 & 9720 & 44,323 & 175,925 \\
\hline $\begin{array}{l}\text { Iraguen and Ortuzar } \\
\text { (2004) }\end{array}$ & 0.39 & 176 & 4292 & 6343 & 9769 & 44,273 & 175,875 \\
\hline $\begin{array}{l}\text { Hojman et al. (2005) (road } \\
\text { safety-route 5) }\end{array}$ & 0.40 & 180 & 4292 & 6348 & 9774 & 44,269 & 175,871 \\
\hline $\begin{array}{l}\text { Hojman et al. (2005) (road } \\
\text { safety-route 68) }\end{array}$ & 0.38 & 171 & 4292 & 6339 & 9765 & 44,278 & 175,880 \\
\hline $\begin{array}{l}\text { GreenLabUC (2014) (road } \\
\text { safety) }\end{array}$ & 0.82 & 369 & 4292 & 6537 & 9963 & 44,080 & 175,682 \\
\hline $\begin{array}{l}\text { GreenLabUC (2014) (air } \\
\text { pollution) }\end{array}$ & 5.40 & 2430 & 4292 & 8598 & 12,024 & 42,019 & 173,621 \\
\hline
\end{tabular}

(a) VSL in million dollars. (b) Risk of death component $=$ risk of death $\times$ value of a statistical life. According to data of the Catalan Transplant Foundation, the risk of death in a kidney extraction surgery is $0.045 \%$. (c) For quality risk compensation, we use the risk of a non-fatal complication $\times$ Value of statistical injury estimated replicating Parada-Contzen et al. (2013). The risk of a non-fatal complication is $13 \%$. (d) For every row, there is a time loss compensation of US\$1876 included in the reservation price. (e) Savings in costs consider only savings to the health system. Benefits in QALY consider gains of improving the quality of life of patients after receiving an organ. To compute these values, we subtract the reservation price to the values estimated by Harrison et al. (2010)

values are presented in Table 5 (columns 1 and 2). Except for one value (GreenLabUC 2014), the estimates for VSL are similar in magnitude across stated preference studies. Consequently, this estimate drives large intervals in the efficiency evaluation. Since not 
all papers in consideration estimate the VSI for Chile, we first use the VSI estimated under the hedonic wage method.

We compute every component of the reservation price and the reservation price itself for every VSL found in the state preference literature (see columns 3, 4 and 5 from Table 5). Since the VSL vary across studies, the reservation price and its corresponding efficiency also vary. As before, we compute savings in costs and savings in cost plus benefits in life quality by subtracting the reservation prices from the benefits per donor provided by (Harrison et al. 2010). ${ }^{6}$ Results for the efficiency analysis for all available SP values are presented in columns 7 and 8 of Table 5 . In general, we estimate reservation prices between US $\$ 6294$ and US $\$ 8598$, predicting efficiency gains between US $\$ 42,019$ and US\$175,925.

Lastly, Table 6 presents the reservation price and savings under alternative values for the VSI. First, based on the results of Hojman et al. (2005), we define the VSI to be $40 \%$ of the estimated VSL. They find that the VSI is $41 \%$ for one of the cases and $50 \%$ for the other. Here, we use the lowest proportion. We then try three alternative cases with VSI values of US $\$ 10,000$, US $\$ 20,000$, and US $\$ 30,000$. As before, savings are computed using the references values from Harrison et al. (2010). The reservation price ranges from US $\$ 3302$ to US $\$ 285,106$, and efficiency gains (losses) range from US $\$ 178,917$ to US\$(234,489).

\section{Discussion and conclusion}

Using labor market estimates of the value of life and safety, on average, we estimate a compensation for living donors of US\$12,347, finding a net benefit ranging from US $\$ 38,269$ to US $\$ 169,871$. As we introduce variation across the wage distribution, we find compensation in the range of US\$4214 to US\$83,953 to induce donations, as well as savings from negative levels US $\$(29,912)$ to US $\$ 181,431$ per additional donor, depending on the wage distribution. As a result, the savings per donors allow for the compensation of donors at the 95th percentile of the wage distribution. Accordingly, we argue that it would be efficient to introduce a participation premium to prevent unequal payments across the distribution. The premium ranges roughly between US $\$ 300$ and US $\$ 30,000$ per donor. Moreover, the efficiency gains are higher when considering stated preference estimates of life and safety.

Despite the efficiency gains, the literature has not established how compensation to living donors would increase the number of donations. To the best of our knowledge, this is the first paper to estimate the value of a kidney for a donor using her willingness to pay for avoiding a kidney disease. From the analysis, we conclude that the compensation computed based on Becker's analysis should not be enough to increase donations. Consequently, we propose donation premiums for effectively inducing donation, computed by considering the donor's willingness to accept payments. The premium ranges roughly between US $\$ 300$ and US $\$ 30,000$, and its introduction is efficient up to at least the 90th percentile of the distribution when only considering

${ }^{6}$ For example, for Ortuzar et al. 2000 (road safety) savings to the system in costs equal US\$44, $143=50,616-6474$ and savings to the system in costs plus QALY benefits equal US\$175,745 =182,218 - 6474. 
Table 6 Compensation and Savings under different quality risk compensations (US\$ of 2013)

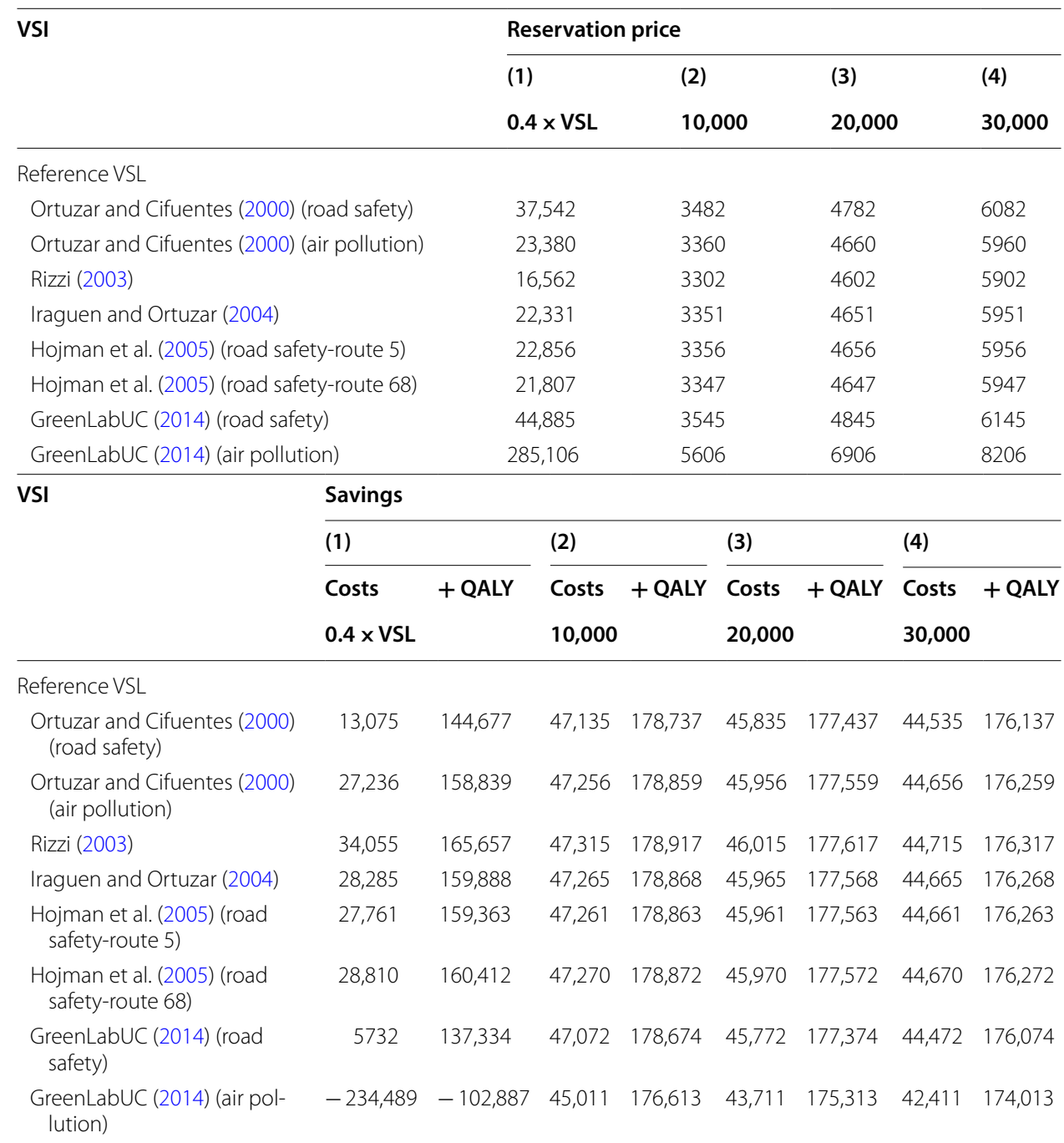

(a) Savings in costs consider only savings to the health system. Benefits in QALY consider gains of improving the quality of life of patients after receiving an organ. To compute these values, we subtract the reservation price to the values estimated by Harrison et al. (2010)

savings in costs without benefits in quality of life, and efficient for the entire distribution when adding QALY benefits.

The set of VSL and VSI estimates we use in the main set of results are among the highest labor market estimates found in the literature. Viscusi and Masterman (2017) report that among the best-set estimates, the median for the VSL for the United States is US\$9.6 million and US\$22.7 million at the 90th percentile of the distribution. For other countries, the median VSL estimate is US\$7.8 million and US\$39.4 at the 90th percentile of the distribution. For this analysis, if lower estimates are used, then the efficiency gains of introducing payments to living donors would be larger.

Since payments to donors have not been generally implemented, it is hard to compare our range of estimated compensation with actual payments. For comparison 
matters, we now consider the scarce evidence from black markets. For example, reports from kidney black-market sales indicate prices in the range of US $\$ 10,000$ to US\$20,000. Most of these sales come from Asia and Latin America. Specifically, there is evidence of sales in Brazil with prices from approximately US\$2000 to US $\$ 10,000$, in the Philippines from US $\$ 2500$ to US $\$ 10,000$, in Turkey from US $\$ 3000$ to US $\$ 10,000$, and in India from US $\$ 1000$ to US\$2000 (Beard et al. 2013; Becker and Elias 2007). From these countries, Brazil might be the most similar to the Chilean structure. Values from Brazil are in similar ranges than compensations estimated for Chilean between the 5 and $50 \%$ of the wage distribution. Generally, these amounts from developing countries are in the same range than estimates for the first half of the Chilean wage distribution (50th percentile), except for India whose values are similar to the reservation prices of the bottom $5 \%$ of the distribution.

In developed countries, evidence from illegal transactions shows prices up to US $\$ 100,000$ for the United States and from US $\$ 9000$ to US $\$ 12,000$ for England. On the other hand, evidence from the Israeli reform predicts that out-of-pocket direct and indirect costs for actual living kidney donors increased to US $\$ 20,000$ (Tushla et al. 2015). Estimates for Canada suggest that the average productivity loss for living donors may rise to US\$6700, equivalent to a compensation for recovery time of US\$1876 (Klarenbach et al. 2014).

Our results are consistent with the findings in the literature. For the U.S., Becker and Elias (2007) estimate an efficiency gain of US $\$ 122,700$ per donor. Held et al. (2016) finds that a conservative compensation of US $\$ 45,000$ per donor would generate total net welfare gain for society of US $\$ 46$ billion per year. However, there is little research on compensation estimates for developing countries, and we believe that this analysis could be extended to other Latin-American countries. For extrapolation of results, it is important to note again that Chile is classified as a developing country by the International Monetary Fund and as a high-income OCDE country by the World Bank.

Note that the wage for the wealthiest segment of the Chilean population (99th percentile) is in similar ranges to the average annual American salary. ${ }^{7}$ Viscusi and Masterman (2017) report an average wage for VSL studies in the U.S. between of roughly US $\$ 45,000$ for U.S. government and from the Census of Fatal Occupational Injuries (CFOI) data sources, and about US\$58,000 for U.S. Non-government sources. Based on this, we could compare the compensation estimated by Becker and Elias (2007) to the US $\$ 80,528$ estimated for Chileans in the 99th percentile and the option value of US\$119,488.

An advantage of introducing compensation payable by a third party is that exclusions in access for organs due to the monetary constraints can be prevented. We think that this policy helps patients who currently may not have access to necessary medical treatment. This access argument might be especially important in developing countries. Res et al. (2017) estimate that $93 \%$ of patients receiving renal replacement treatment reside in high- or high-middle-income countries, while only $7 \%$ reside in low-income countries.

Additionally, compensations could be introduced as credit or a payment to the donors' health insurance contract for the recommended follow-up consultations with medical 
transplantation team (Glotzer et al. 2013). Compensations could also pay improved psychological treatments as there is evidence that more and better psychological care for living donors should be provided (Giessing et al. 2004). There could also be space for educational programs and campaigns to promote donations and to promote other initiatives to increase donation rates, such as the Donor Action program (Roels et al. 2003). In this paper, we do not address crowd-out of altruistic donations since our strategy consists on evaluating indifference values for an average person.

Acknowledgements

Marcela Parada-Contzen thanks the funding granted by Fondecyt (National Fund for Scientific and Technological Development-Chile), Project No. 3180155.

\section{Authors' contributions}

Both the authors analyzed data, discussed empirical findings, and extensions. Both the authors equally contribute in writing the manuscript. Both authors read and approved the final manuscript.

\section{Funding}

Marcela Parada-Contzen receive funding granted by Fondecyt (National Fund for Scientific and Technological Development-Chile), Project No. 3180155.

\section{Availability of data and materials}

All data are publicly available as explain in Sect. 3.2. The dataset for replicating the study can be obtained at http://obser vatorio.ministeriodesarrollosocial.gob.cl/casen/casen_usuarios.php.

\section{Ethics approval and consent to participate}

Not applicable.

\section{Consent for publication}

Not applicable.

\section{Competing interests}

The authors declare that they have no competing interests.

\section{Author details}

${ }^{1}$ Departamento de Ingeniería Industrial, Facultad de Ingeniería, Universidad de Concepción, Edmundo Larenas 219, Concepción, Chile. ${ }^{2}$ Facultad de Economía y Negocios, Universidad del Desarrollo, Ainavillo 456, Concepción, Chile.

Received: 10 December 2018 Accepted: 28 June 2019

Published online: 10 July 2019

\section{References}

Abadie A, Gay S (2006) The impact of presumed consent legislation on cadaveric organ donation: a cross-country study. J Health Econ 25(4):599-620

Alvo M (2009) Prevención de la enfermedad renal crónica l: aspectos generales. Medwave 9:1

Barnett A, Kaserman D, Adams A (1999) Market for organs: the question of supply. Contemp Econ Pol 17(2):147-155

Barnett W, Michael S, Walker D (2001) A free market in kidneys: efficient and equitable. Indep Rev 5(3):373-385

Beard R, Kaserman D, Osterkamp R (2013) The global organ shortage: economic causes, human consequences, policy responses. Stanford University Press, Palo Alto

Becker G, Elias J (2007) Introducing incentives in the market for live and cadaveric organ donations. J Econ Persp 21(3):3-24

Bellavance F, Dionne G, Lebeau M (2009) The value of a statistical life: a meta-analysis with a mixed effects regression model. J Health Econ 28(2):444-464

Bilgel F (2013) The effectiveness of transplant legislation, procedures and management: cross-country evidence. Health Policy 110(2):229-242

Bilgel F, Gelle B (2015) Financial incentives for kidney donation. A comparative case study using synthetic controls. J Health Econ 43:103-117

Bowland B, Beghin J (2001) Robust estimates of value of a statistical life for developing economies. J Policy Model 23(4):385-396

Brooks M (2003) A free market in kidneys would be efficient and equitable: a case of too much romance. Indep Rev 7(4):587-594

Chilean National Health Survey (2003) Ministry of Health, Chile

De Blaeij A, Florax R, Rietveld P, Verhoef E (2003) The value of statistical life in road safety: a meta-analysis. Accid Anal Prev 35(6):973-986

Diesel J (2010) Do economists reach a conclusion on organ liberalization? Econ J Watch 7(3):320-336

Dominguez J, Harrison R, Atal R (2011) Cost-Benefit Estimation of Cadaveric Kidney Transplantation: the Case of a Developing Country. Transpl Proc 46(6):2300-2304

Evans R, Kitzmann D (1998) An economic analysis of kidney transplantation. Surg Clin 78(1):149-174 
Flores J (2010) Enfermedad renal crónica: epidemiología y factores de riesgo. Revista Medica Clinica Las Condes 21(4):502-507

Gaston R et al (2006) Limiting financial disincentives in live organ donation: a rational solution to the kidney shortage. Am J Transpl 6(11):2548-2555

Giessing M et al (2004) Quality of life of living kidney donors in Germany: a survey with the validated short form-36 and giessen subjective complaints list-24 questionnaires. Transplantation 78(6):864-872

Glotzer $O$ et al (2013) Long-term quality of life after living kidney donation. Transpl Proc 45(9):3225-3228

GreenLabUC (2014) Estimación del valor de la vida estadística asociado a contaminación atmosférica y accidentes de tránsito, s.l.: s.n

Hammitt J, Robinson L (2011) The income elasticity of the value per statistical life: transferring estimates between high and low income populations. J Benafit Cost Anal 2(1):1-29

Harrison R, Dominguez JLL, Contreras D, Atal R (2010) Evaluacion del sistema de trasplante en Chile: propuestas de intervencion. In: Propuestas para Chile. Camino al Bicentenario. s.l.:Pontificia Universidad Catolica de Chile

Held P, Port F (2003) The impact of the organ shortage beyond the immediate loss of life: social, medical, and economic costs. S.l., s.n

Held P, McCormick F, Ojo A, Roberts J (2016) A cost-benefit analysis of government compensation of kidney donors. Am J Transpl 16(3):877-885

Hojman P, Ortuzar J, Rizza L (2005) On the joint valuation of averting fatal and severe injuries in highway accidents. J Saf Res 34(6):377-386

Howard D (2007) Producing organ donors. J Econ Persp 21(3):25-36

International Registry in Organ Donation and Transplantation, 2017. IRODaT Newsletter 2017

Iraguen P, Ortuzar J (2004) Willingness-to-pay for reducing fatal accident risk in urban areas: an Internet-based Web page stated preference survey. Accid Anal Prev 36(4):513-524

Klarenbach S et al (2014) Economic consequences incurred by living kidney donors: a Canadian multi-center prospective study. Am J Transplant 14(4):916-922

Lavee J et al (2013) Preliminary marked increase in the national organ donation rate in Israel following implementation of a new organ transplantation law. Am J Transpl 13(3):780-785

Liverman C, Childress J (2006) Organ donation: opportunities for action. National Academies Press, Washington, D.C

Matas A (2004) The case for living kidney sales: rationale, objections and concerns. Am J Transplant 4(12):2007-2017

Matas A, Schnitzler M (2004) Payment for living donor (vendor) kidneys: a cost-effectiveness analysis. Am J Transpl 4(2):216-221

Miller T (2000) Variations between countries in values of statistical life. J Transp Econ Policy 34(2):169-188

Mossialos E, Costa-Font J, Rudisill C (2008) Does organ donation legislation affect individuals' willingness to donate their own or their relative's organs? Evidence from European Union survey data. BMC Health Serv Res 8(1):48

Ortuzar J, Cifuentes WH (2000) Application of willingness-to-pay methods to value transport externalities in less developed countries. Environ Plan A 32(11):2007-2018

Parada-Contzen M (2019) The Value of a statistical life for risk-averse and risk-seeking individuals. Risk Anal. https://doi. org/10.1111/risa.13329

Parada-Contzen M, Riquelme-Won A, Vasquez-Lavin F (2013) The value of a statistical life in Chile. Empir Econ 45(3):1073-1087

Rees M et al (2017) Kidney exchange to overcome financial barriers to kidney transplantation. Am J Transpl 17(3):782-790

Rizzi LOJ (2003) Stated preference in the valuation of interurban road safety. Accid Anal Prev 35(1):9-22

Roels $L$ et al (2003) Cost-benefit approach in evaluating investment into donor action: the German case. Transpl Int 16(5):321-326

Roth A, Sönmez T, Unver U (2005) Pairwise kidney exchange. J Econ Theory 125(2):151-188

Schnier K, Merion R, Turgeon N, Howard D (2018) Subsidizing altruism in living organ donation. Econ Inq 56(1):398-423

Stoler A et al (2017) Incentivizing organ donor registrations with organ allocation priority. Health Econ 26(4):500-510

Tushla L et al (2015) Living-donor kidney transplantation: reducing financial barriers to live kidney donation-recommendations from a consensus conference. Clin J Am Soc Nephrol 10(9):1696-1702

Venkataramani A, Martin E, Vijayan A, Wellen J (2012) The impact of tax policies on living organ donations in the United States. Am J Transpl 12(8):2133-2140

Viscusi WK (1993) The value of risks to life and health. J Econ Liter 31(4):1912-1946

Viscusi WK, Aldy J (2003) The value of a statistical life: a critical review of market estimates throughout the world. J Risk Uncertainty 27(1):5-76

Viscusi WK, Masterman C (2017) Anchoring biases in international estimates of the value of a statistical life. J Risk Uncertainty 54(2):103-128

Wellington A, Sayre E (2011) An evaluation of financial incentive policies for organ donations in the United States. Contemp Econ Policy 31(4):1912-1946

\section{Publisher's Note}

Springer Nature remains neutral with regard to jurisdictional claims in published maps and institutional affiliations. 